\title{
Exploring Acceptability and Possible Therapeutic Implication of Lagenaria Siceraria Pulp Powder
}

\author{
Shweta Sharma ${ }^{1}$, Charu Katare ${ }^{1 *}$ and GBKS Prasad ${ }^{2}$ \\ ${ }^{1}$ Department of Home Science (Food and Nutrition), Jiwaji University, India \\ ${ }^{2}$ Department of Biochemistry, Jiwaji University, India
}

Submission: May 20, 2017; Published: June 08, 2017

*Corresponding author: Charu Katare, Department of Home Science (Food and Nutrition), Jiwaji University, India, Tel: 0751-2625495;

Fax: 0751-2438173; Email: cskatare@gmail.com

\begin{abstract}
This is a preliminary study carried out to explore blood glucose lowering potential of fibre obtained from bottle gourd pulp which was procured as a by-product of the bottle gourd juice extraction. Dried bottle gourd pulp powder and whole bottle gourd pulp powder (DBPP\&WBP) supplement was administered to normal healthy human subjects and blood glucose was monitored for two hours and its influence on blood glucose was evaluated. All the subjects exhibited significantly lower levels of plasma glucose $(\mathrm{p}<0.05)$ after consumption of DBPP \&WBP at all points of monitoring in comparison to blood glucose response on oral glucose administration. Incremental area under curve for the both the supplements was measured followed by calculation of GI. Statistical analysis using Anova demonstrated a significant reduction $(\mathrm{p}<0.05)$ in IAUC after consumption of DBPP and WBP supplement in subjects when compared to IAUC of oral glucose. Blood glucose values showed a lower glucose response on administration of DBPP whereas WBP administration demonstrated relatively a higher glucose response with regards to the mean scores at the 120 minute of intake. It was evident in this investigation that DBPP intake has clear benefits regarding plasma blood glucose indicating that vegetable pulp may be used efficiently for therapeutic purposes.
\end{abstract}

Keywords: Bottle gourd; Fiber; Blood glucose level; IAUC

Abbreviations: Units: mg/dl; Drink 1: Buttermilk+Glucose; Drink 2: Buttermilk+Glucose+DBPP; Drink 3: Buttermilk+DBPP; Drink 4: Buttermilk+Glucose+WBP; Drink 5: Buttermilk+WBP

\section{Introduction}

It is known for a long time that dietary fiber (DF) plays important roles in the health of humans. Initially, the interest for possible health benefits of regular DF consumption was stimulated by epidemiological studies, which linked a lack of DF to constipation, diverticulitis, cancer of the large bowel, as well as the risk of obesity, cardiovascular disease and type 2 diabetes [1] Diabetes mellitus is an ever increasing problem in all over the world and is a major disorder of industrialized and non-industrialized societies (World Health Organization, 1980). The American Diabetes Association recommends a specific diet as part of medical nutrition therapy for secondary and tertiary prevention in patients with type 2 diabetes mellitus. This diet includes consumption of fiber-rich foods [2]. Fiber has been studied in the treatment of diabetes for many years because increased fiber content decreases the glycemic index of foods [3]. The theory, then, is that the decreased glycemic index would lead to smaller increases in blood glucose, and thus reduced blood glucose and HbA1c levels. High fiber intake has also been linked to a decreased risk of diabetes [4]. Fiber is known to enhance digestive process, stimulates bowel movement, lowers cholesterol, and exerts a positive influence on blood sugar levels [5]. The importance of dietary fibre in the prevention of diabetes mellitus, obesity, coronary heart diseases, colon cancer and diverticular diseases among others, has caused more awareness on the essence of consuming foods with high fiber content [6,7].

Diet rich in fruits and vegetables serve as a source of vitamins and minerals and high consumption of fruits and vegetables provides health benefits due to their antioxidant constituents. They also contain non-nutritive components such as dietary fiber. Residue from the processing of fruits and vegetables or the residue remaining after extraction of juice is called pulp, is traditionally considered as an environmental problem, and is being increasingly recognised as source for obtaining high fiber and products. By-products from the fruit and vegetable industry, in particular, are of interest since they are inexpensive and available in large quantities. The aim of this study was to use 
bottle gourd (Lagenaria Siceraria) pulp remaining as a leftover material after juice extraction to formulate functional vegetable supplement which may be used for therapeutic purpose.

\section{Materials and Methods}

Bottle gourd pulp was procured as a by-product of bottle gourd juice extraction. The pulp was then dehydrated in hot air oven at $40^{\circ} \mathrm{C}-50^{\circ} \mathrm{C}$ for at least two days. The dehydrated bottle gourd pulp was crushed and ground in a commercial mixer so that the dried pulp could be obtained in powder form. Dried pulp was pulverized and passed through a 100-mesh sieve; a free flowing powder was obtained which was sealed in air tight container at ambient temperature to observe its shelf life. From consumer point of view, the primary consideration for selecting and eating a food commodity is the product's palatability or eating quality, and other quality parameters, such as nutrition Table 1: Overall acceptability of DBPP and WBP in water and butter milk.

\begin{tabular}{|c|c|c|c|c|c|c|c|c|}
\hline \multirow{2}{*}{ Overall Acceptability } & DBPP & WBP & DBPP & WBP & DBPP & WBP & DBPP & WBP \\
\hline & \multicolumn{2}{|c|}{$1 \mathrm{~g}$} & \multicolumn{2}{|c|}{$3 g$} & \multicolumn{2}{|c|}{$5 g$} & \multicolumn{2}{|c|}{$7 \mathrm{~g}$} \\
\hline Sensory Evaluation of Supplement in Water & 8.7 & 8.6 & 8.3 & 8.2 & 7.9 & 7.6 & 4.2 & 4 \\
\hline Sensory Evaluation of supplement in Butter Milk & 8.8 & 8.7 & 8.4 & 8.4 & 8.2 & 8 & 4.6 & 4.4 \\
\hline
\end{tabular}

Table 2: Summary of one way ANOVA on scores of 60 minute reading of glycemic response with all the five Different Drinks.

\begin{tabular}{|c|c|c|c|c|c|}
\hline \multirow{2}{*}{ Source } & $\begin{array}{c}\text { Type III } \\
\text { Sum of } \\
\text { Squares }\end{array}$ & df & $\begin{array}{c}\text { Mean } \\
\text { Squares }\end{array}$ & f & Remark \\
\cline { 1 - 3 } Intervention & 15945.200 & 4 & 3986.300 & & \\
\cline { 1 - 4 } Error & 4982.800 & 20 & 249.140 & \multirow{2}{*}{16.000} & $\mathrm{p}<0.05$ \\
\hline Total & 553828.000 & 25 & & \\
\hline Corrected Total & 20928.000 & 24 & & \\
\hline
\end{tabular}

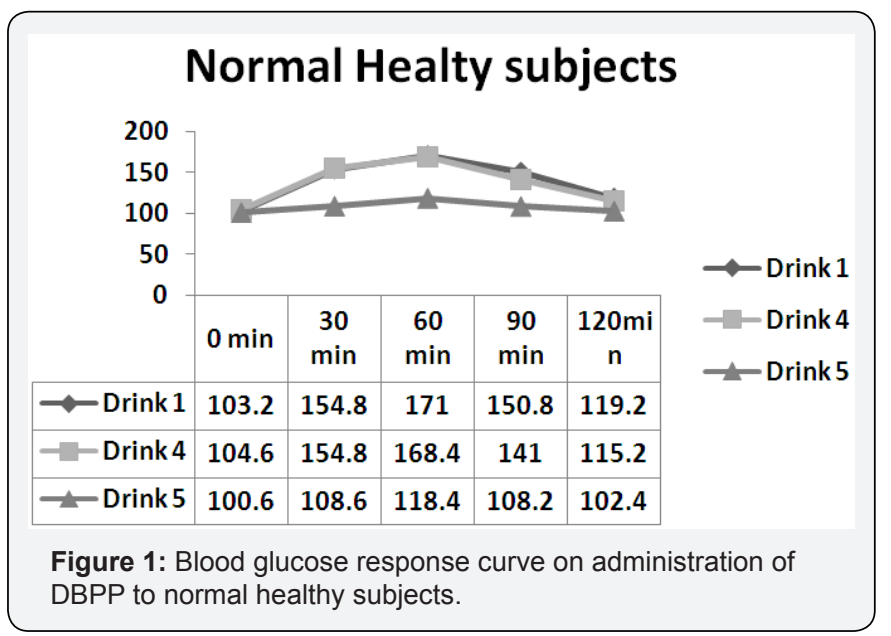

Abbrevations: Unit=mg/dl; Drink 1(D 1)=Butter milk $(200 \mathrm{ml})+$ Glucose $(50 \mathrm{~g})$; Drink $4(\mathrm{D} 4)=$ Buttermilk $(200 \mathrm{ml})+$ Glucose $(50 \mathrm{~g})+$ WBP $(5 \mathrm{~g})$; Drink 5(D5)=Buttermilk (200ml)+WBP (5g)

DBPP was evaluated to see how it influences glycemic status in normal healthy subjects, hence glycemic response and GI (glycemic index) of DBPP drink was determined using standard protocol. To determine glycemic response and GI of and wholesomeness are secondary [8,9]. To determine acceptability of DBPP (dehydrated bottle gourd pulp powder), a drink was prepared using various doses of DBPP i.e. $1 \mathrm{~g}, 3 \mathrm{~g}$, $5 \mathrm{~g}$, and $7 \mathrm{~g}$ in $200 \mathrm{ml}$ water with a pinch of salt and provided to the tasting panel on different days for evaluating the drink on sensory attributes. Ten (10) Professors and 4 Postgraduate students of the Department of Home science, Foods and Nutrition Govt.KRG PG College, Jiwaji University Gwalior, were the panellist to judge the beverage prepared using DBPP. In the same manner a drink of DBPP with $200 \mathrm{ml}$ thin buttermilk was also evaluated organolepticall by the tasting panel. The Sensory evaluation was carried out using 9 point hedonic scale system for various attributes like taste, colour, flavour consistency and appearance so that acceptability may be determined [10]. DBPP in buttermilk was found to be more acceptable (Table $1 \& 2$ ).
DBPP supplement, 10 normal healthy subjects were selected. The subjects were in the age group of 40-60 years, vegetarian, sedentary active and exhibited BMI in normal range. All the subjects were explained the study protocol for determination of GI and a written consent for voluntary participation were obtained. Following procedure was adopted for determination of GI (Figure 1).

The study was carried out at SOS in Biochemistry, Jiwaji University, Gwalior MP. All the subjects were asked to attend the testing session after a 10-12 hour overnight fast on the day test was to be performed, having been instructed not to consume unusually large meals, drink alcohol or exercise vigorously on the previous day, and to avoid cycling or walking to the laboratory. On the first day $50 \mathrm{~g}$ glucose dissolved in $200 \mathrm{ml}$ of thin buttermilk (Drink 1) was administered as reference food to normal healthy subjects on empty stomach early in the morning. Blood glucose level was measured in capillary whole blood obtained by finger prick (Accu-Chek Roche Diagnostics India Pvt Ltd, Mumbai) in the fasted state at 0 and after 30, 60, 90 and 120 minutes on consumption of the reference food. A curve was constructed on the basis of the blood glucose values obtained at every 30 minute interval and the increment area under the curve (IAUC) was calculated for by the trapezoidal rule (WHO/FAO 1980).

\section{DBPP supplement}

Drink 1= Buttermilk + glucose (D1)

Drink 2= Buttermilk + glucose +DBPP (D2)

Drink 3= Buttermilk + DBPP (D3)

Drink 4=Buttermilk + glucose +WBP (D4)

Drink 5= Buttermilk +WBP (D5) 
Similar procedure was repeated with a gap of two days for administering D2 and D3 in $200 \mathrm{ml}$ buttermilk and blood glucose curve was plotted for calculating IAUC. Blood glucose curves for D1, D2 and D3 were compared with special reference to peak blood glucose values obtained after administration of the different drinks. The present study intended to use dried bottle gourd pulp powder (DBPP) in the form of fiber supplement. To observe whether there was any difference in glycemic response elicited on consumption of DBPP against consumption of whole bottle gourd powder (WBP) the above mentioned procedure was repeated by administering the drinks (D4 and D5) in the same manner using WBP and the results were compared.

Overall acceptability is inclusive of sensory parameters viz. taste, flavour, colour, appearance and consistency

\section{Discussion}

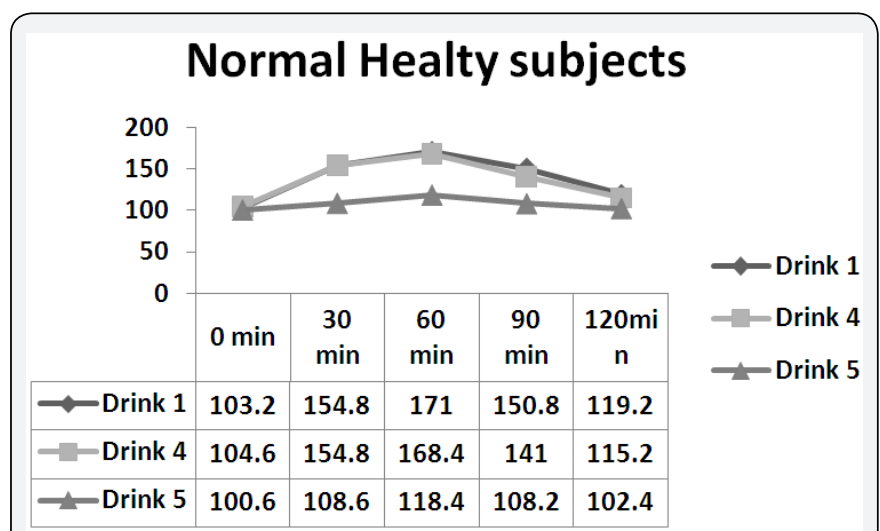

Figure 2: Blood glucose response curve on administration of WBP to normal healthy subjects.

Abbrevations: Unit=mg/dl; Drink 1(D 1)=Butter milk (200ml)+Glucose $(50 \mathrm{~g})$; Drink $4(\mathrm{D} 4)=$ Buttermilk $(200 \mathrm{ml})+$ Glucose $(50 \mathrm{~g})+$ WBP $(5 \mathrm{~g})$; Drink 5(D5)=Buttermilk (200ml)+ WBP (5g)

The study intended to use bottle gourd pulp as a fiber supplement and to explore possibility of enrichment of food formulations with DBPP which may serve as good source of functional DF simultaneously preventing wastage of pulp obtained after extraction of juice from the fruit. To determine acceptability of DBPP organoleptic evaluation was carried out. DBPP was evaluated against WBP to find out whether there was any difference in acceptability and therapeutic implication of the fiber in two different forms. The sensory attributes considered important were taste, flavour, colour, appearance and consistency (admissibility with the liquid). On the basis of these attributes overall acceptability was determined by a panel of judges. Two sets of test drinks containing DBPP and WBP were prepared in different doses viz.1, 3, 5 and $7 \mathrm{~g}$ respectively in water as well as in buttermilk and offered to panel of judges on different days. Overall acceptability scores of the drink containing DBPP and WBP was 8 and 8.2 respectively indicating marginal difference in values for sensory parameters, pointing out that both the fiber supplements were almost similar in acceptability and the taste was appreciated by panellists. The maximum acceptable amount of DBPP was 5g and DBPP in buttermilk was more acceptable than in water (Table 1), therefore a supplement drink was prepared using $5 \mathrm{gm}$ of fiber powder (Figure 2).

Any novel food is of more value when it exhibits therapeutic potential. Reference drink viz. buttermilk with glucose (D1), test drinks buttermilk and glucose with DBPP (D2), buttermilk with DBPP (D3), buttermilk and glucose with WBP (D4) and buttermilk with WBP (D5) were administered to healthy subjects for determination of glycemic response. All the subjects exhibited significantly lower levels of plasma glucose after consumption of D2 to D5 at all points of monitoring in comparison to oral glucose (D1) administration. It is evident in the Table 2 that the f value for group being 16.0 is significant with $\mathrm{df}=4 / 20$. It indicates that the mean scores of glycemic response of the test drinks administered at the sixtieth minute buttermilk along with glucose (D1), buttermilk along with glucose and dried bottle gourd pulp powder (D2), buttermilk along with dried bottle gourd pulp powder (D3), buttermilk along with glucose and whole bottle gourd powder (D4) and the buttermilk with whole bottle gourd powder (D5) differed significantly. It was also noticed that there was no significant difference in the Duncan test to say that a particular test drink proved better. But the D2 and D3 showed a lower glycemic response and D1 revealed a higher glycemic response with regard to the mean scores at the $60^{\text {th }}$ minute of intake. This is a little interesting that dried bottle gourd pulp powder proved better influencing than the whole bottle gourd powder after 60 minutes of intake (Table 3). This ensures that the effect of bottle gourd start to significantly influence the blood glucose levels even on the $60^{\text {th }}$ minute of intake Blood glucose values at the end of two hours indicate that the $\mathrm{f}$ value for group being 4.316 is significant with $\mathrm{df}=4 / 20$ (Table 4). It indicates the mean scores of glycemic response of the reference (D1) and test drinks (D2 to D5) administered differed significantly at the one hundred and twentieth minute. Duncan test pointed out that there was no significant difference to say that a particular test drink proved better. But the D3 showed a lower glycemic response and D5 revealed a higher glycemic response with regard to the mean scores at the $120^{\text {th }}$ minute of intake (Table 5). This approves that dried bottle gourd pulp powder proved better influencing than the whole bottle gourd powder even after 120 minutes of intake. This certainly shows that the effect of bottle gourd start to significantly influence the blood glucose levels even after two hours of intake. Similar trend of blood glucose modulation was observed in an uncontrolled study of five patients with type 2 diabetes consuming one-half teaspoonful twice daily of dried aloe sap (administered for 4-14 weeks) resulted in a mean $\mathrm{A} 1 \mathrm{C}$ decrease from 10.6 to $8.2 \%, \mathrm{P}$ value not reported [11]. Mean fasting glucose decreased from 273 to $151 \mathrm{mg} / \mathrm{dl}(\mathrm{P}<0.001)$ [12]. Yet another study reveal that methanolic fruit pulp extract of C.sativus was administered to the alloxan induced diabetic rats decreased fasting blood glucose significantly $(\mathrm{p}<0.05)$ from $231.25 \pm 1.11$ to $82.25 \pm 1.55$ at $500 \mathrm{mg} / \mathrm{Kg}$ body weight [13]. 
Table 3: Duncan test-the post hoc test to know which test drinks proves better at 60 minutes.

\begin{tabular}{|c|c|c|c|}
\hline \multirow{2}{*}{ Intervention } & $\mathbf{N}$ & \multicolumn{2}{|c|}{ Subset for alpha =.05 } \\
\cline { 2 - 4 } & $\mathbf{1}$ & $\mathbf{2}$ & $\mathbf{1}$ \\
\hline Drink 3 & 5 & 112.6000 & \\
\hline Drink 5 & 5 & 118.4000 & \\
\hline Drink 2 & 5 & & 159.6000 \\
\hline Drink 4 & 5 & & 168.4000 \\
\hline Drink 1 & 5 & & 171.0000 \\
\hline Sig. & & .568 & .293 \\
\hline
\end{tabular}

Abbreviations: Units: $\mathrm{mg} / \mathrm{dl}$; Drink 1: Buttermilk+Glucose; Drink 2: Buttermilk+Glucose +DBPP; Drink 3: Buttermilk+DBPP; Drink 4: Buttermilk+Glucose+WBP; Drink 5: Buttermilk+WBP.

Table 4: Summary of one way ANOVA on scores of 120 minute reading of glycemic response with all the five different drinks.

\begin{tabular}{|c|c|c|c|c|c|}
\hline Source & $\begin{array}{c}\text { Type III sum of } \\
\text { squares }\end{array}$ & df & $\begin{array}{c}\text { Mean } \\
\text { Squares }\end{array}$ & f & Remark \\
\cline { 1 - 3 } Intervention & 1411.040 & 4 & 352.760 & & \\
\hline Error & 1634.800 & 20 & 81.740 & \multirow{2}{*}{4.316} & $\mathrm{P}<0.05$ \\
\hline Total & 299635.000 & 25 & & & \\
\hline $\begin{array}{c}\text { Corrected } \\
\text { Total }\end{array}$ & 3045.840 & 24 & & & \\
\hline
\end{tabular}

Table 5: Duncan test-the post hoc test to know which test drinks proves better 120 minutes.

\begin{tabular}{|c|c|c|c|}
\hline \multirow{2}{*}{ Intervention } & $\mathbf{N}$ & \multicolumn{2}{|c|}{ Subset for Alpha =.05 } \\
\cline { 2 - 4 } & $\mathbf{1}$ & $\mathbf{2}$ & $\mathbf{1}$ \\
\hline Drink 3 & 5 & 99.2000 & \\
\hline Drink 5 & 5 & 102.4000 & \\
\hline Drink 2 & 5 & 108.6000 & 108.6000 \\
\hline Drink 4 & 5 & & 115.2000 \\
\hline Drink 1 & 5 & & 119.2000 \\
\hline Sig. & & .135 & .093 \\
\hline
\end{tabular}

Abbreviation: Units: mg/dl; Drink 1: Buttermilk+Glucose; Drink 2: Buttermilk+Glucose +DBPP; Drink 3: Buttermilk+DBPP; Drink 4: Buttermilk+Glucose+WBP; Drink 5: Buttermilk+WBP Drink 3=buttermilk+DBPP

Table 6: IAUC and GI on administration of DBPP and WBP in normal healthy subjects.

\begin{tabular}{|c|c|c|c|c|}
\hline \multirow{2}{*}{$\begin{array}{c}\text { Test \& } \\
\text { Reference } \\
\text { Food }\end{array}$} & \multicolumn{2}{|c|}{ IAUC } & \multicolumn{2}{c|}{ GI } \\
\cline { 2 - 5 } & Mean & SD & Mean & SD \\
\hline Drink 1 & 291.7 & 37.69 & - & - \\
\hline Drink 2 & 211.7 & 60.24 & 72.9 & 17.82 \\
\hline Drink 3 & 40.6 & 39.29 & 14.0 & 11.71 \\
\hline Drink 4 & 259.5 & 87.05 & 89.3 & 25.11 \\
\hline Drink 5 & 57.2 & 4.96 & 19.9 & 2.98 \\
\hline
\end{tabular}

Abbreviations: Units: $\mathrm{mg} / \mathrm{dl}$; Drink 1: Buttermilk+Glucose; Drink 2: Buttermilk+Glucose +DBPP; Drink 3: Buttermilk+DBPP; Drink 4: Buttermilk+Glucose+WBP; Drink 5: Buttermilk+WBP Drink 3=buttermilk+DBPP
Table 7: Summary of one way ANOVA on mean scores IAUC of subjects who had all the five different drinks.

\begin{tabular}{|c|c|c|c|c|c|}
\hline Source & $\begin{array}{c}\text { Type III sum } \\
\text { of squares }\end{array}$ & df & $\begin{array}{c}\text { Mean } \\
\text { squares }\end{array}$ & f & Remark \\
\hline Intervention & 269939.530 & 4 & 67484.882 & & \\
\hline Error & 56794.408 & 20 & 2839.720 & & \\
\hline Total & 1067455.803 & 25 & & 23.765 & $\mathrm{p}<0.05$ \\
\cline { 1 - 3 } $\begin{array}{c}\text { Corrected } \\
\text { Total }\end{array}$ & 326733.937 & 24 & & & \\
\hline
\end{tabular}

Table 8: Duncan test - the post hoc test to know which test drinks proves better.

\begin{tabular}{|c|c|c|c|}
\hline \multirow{2}{*}{ Intervention } & $\mathbf{N}$ & \multicolumn{2}{|c|}{ Subset for Alpha =.05 } \\
\cline { 2 - 4 } & $\mathbf{1}$ & $\mathbf{2}$ & $\mathbf{1}$ \\
\hline Drink 3 & 5 & 40.6420 & \\
\hline Drink 5 & 5 & 57.1800 & \\
\hline Drink 2 & 5 & & 211.6640 \\
\hline Drink 4 & 5 & & 259.5000 \\
\hline Drink 1 & 5 & & \\
\hline Sig. & & .629 & .171 \\
\hline
\end{tabular}

Abbreviations: Units: $\mathrm{mg} / \mathrm{dl}$; Drink 1: Buttermilk+Glucose; Drink 2: Buttermilk+Glucose +DBPP; Drink 3: Buttermilk+DBPP; Drink 4: Buttermilk+Glucose+WBP; Drink 5: Buttermilk+WBP Drink 3: Buttermilk+DBPP

On the basis of the blood glucose values recorded at 30 minute interval incremental area under curve (IAUC) was calculated (Table 6). It was observed that the mean scores of IAUC of the test drinks administered differed significantly. Analysis by one way ANOVA indicated a significant reduction $(\mathrm{P}<0.05)$ in plasma glucose levels at $30,60,90$, and 120 minutes with formulated Drinks (D2-D5) (Table 7). This signifies that the bottle gourd of any form may influence the IAUC of the test drinks administered to the subjects. GI of D3 and D5 was found to be 14 and 19.9 again indicating the difference in blood glucose modulating effect D3 and D5. There was no significant difference in the Duncan test to say that a particular test drinks proved better. D3 showed a lower IAUC and D1 revealed a higher IAUC with regard to the mean scores at the $120^{\text {th }}$ minute of intake (Table 8). This approves that dried bottle gourd pulp powder proved better influencing than the whole bottle gourd powder in terms of IAUC of subjects too There are studies which point out that foods with a low-glycaemic response have been shown to exert beneficial effects on blood glucose and insulin levels [14], on the incidence of type 2 diabetes and on prolonged satiety [15]. According to a pilot study (mild diabetes), maximum reduction of $73.51 \%$ was observed in glucose levels in animals receiving $200 \mathrm{mg} / \mathrm{kg}$ per day of lyophilized powder of EJ (Eugenia jambolana) after 3 weeks of treatment [16]. Yet another study reported that unripe pulp of Eugenia jambolana elicited significant $(\mathrm{P}<0.05)$ reduction of blood glucose, in diabetes induced albino rats [17] Similar trend of results were shown in the present study and our observations indicate that DBPP may prove to be a fiber supplement with potential to modulate blood glucose level and may serve as complimentary therapy in diabetes. 
Bottle gourd has been investigated for presence of antioxidant activity by [18]. Bottle gourd (L. siceraria) juice was extracted and dried through vacuum distillation to obtain dry mass, followed by freeze drying to get semisolid mass (BGJP) for the purpose of qualitative and quantitative phyto chemical analysis. Whole Bottle gourd powder (WBGP) and pulp powder (PP) remaining after juice extraction were also analyzed. Antioxidant activity was assessed by 1-1, diphenyl-2-picrylhydrazyl radical (DPPH) reducing capacity which showed Ic50 value of $31.0 \pm 0.2 \mathrm{mg} / \mathrm{ml}$ in Whole bottle gourd powder (WBGP). The Ic50 value for ascorbic acid was $27.83 \pm 0.4 \mathrm{mg} / \mathrm{ml}$. Detrmination of total phenolic content demonstrated presence of antioxidant activity in all the samples [19-21]. WBGP was found to contain highest amount whereas L. siceraria pulp powder (PP) showed lowest presence of total phenolic content.

Assssment of total flavonoid and total flavonols content showed the highest level of flavonoids $(440 \mathrm{mg} / \mathrm{g})$ and flavonols $(10.092 \mathrm{mg} / \mathrm{g})$ in WBGP, which is the indicator of presence of antioxidant compounds in Bottle gourd and it's by products which are reported to be beneficial for health specially to combat metabolic stress. Based on the results of this study and studies on antioxidant properties of bottle gourd it may be assumed that bottle gourd pulp is suitable to be utilized for development of products with nutraceutical potential It also appears that pulp which is a major waste from vegetable and fruit processing industry may be utilized for development of products with nutraceutical potential. The study suggests that this fiber may be explored for presence of antioxidants and other bioactive compounds with potential health benefits $[22,23]$.

\section{Conclusion}

To conclude, the evidence available shows that the fiber intake is beneficial has clear benefits regarding plasma blood glucose as DBPP consumption was found to lower the blood glucose level of the subjects at peak as well as at the end of two hours. It appears that dried bottle gourd pulp powder may be efficiently used in food formulations which may have therapeutic implication in derangement of glucose metabolism. The pulp powders also provide another distinct advantage because they may be used as a pure, all-natural edible substance instead of relying on artificial additives that taint the natural color, flavor, and nutritional integrity of the products.

\section{References}

1. Champ M, Langkilde AM, Brouns F, Kettlitz B, Yle CB (2003) Advances in dietary fibre characterisation. 1. Definition of dietary fibre, physiological relevance, health benefits and analytical aspects. Nutr Res Rev 16(1): 71-82.

2. Bantle JP, Wylie-Rosett J, Albright AL, Apovian CM, Clark NG, et al. (2008) Nutrition recommendations and interventions for diabetes: a position statement of the American Diabetes Association. Diabetes Care 31(Suppl 1): S61-S78.

3. Marangoni F, Poli A (2008) The glycemic index of bread and biscuits is markedly reduced by the addition of a proprietary fiber mixture to the ingredients. Nutr Metab Cardiovasc Dis 18(9): 602-605.
4. Wannamethee SG, Whincup PH, Thomas MC, Sattar N (2009) Associations between DFand inflammation, hepatic function, and risk of type 2 diabetes in older men: potential mechanisms for the benefits of fiber on diabetes risk. Diabetes Care 32(10): 1823-1825.

5. Higgins JA (2004) Resistant starch: metabolic effects and potential health benefits. J AOAC Int 87(3): 761-768.

6. Theuwissen E, Mensink RP (2008) Water-soluble dietary fibers and cardiovascular disease. Physiol Behav 94(2): 285-292.

7. Tungland BC, Meyer D (2002) Nondigestible Oligo- and polysaccharides (dietary fiber): their physiology and role in human health and food. Comprehensive Rev in Food Science and Food Safety 1: 73-92.

8. Meiselman HL, Macfie HJH (1996) Food Choice Acceptance and Consumption. Glasgow UK, Backie Academic and Professional p. 239.

9. Lawless, HT, Heymann H (1998) Sensory Evaluation of Food: Principles and Practices. Chapman\& Hall, Newyork, USA.

10. Srilakshmi B (2007) Food Science (4) Sensory evaluation. New Age International (p) Lt., pp. 297-298.

11. Gannam N (1986) The antidiabetic activity of aloes: preliminary clinical and experimental observations. Horm Res 24(4): 288-294.

12. Laura Shane McWhorter, BCPS, FASCP, BC-ADM, CDE (2009) Dietary Supplements for Diabetes: An Evaluation of Commonly Used Products. Diabetes Spectrum 22(4): 206-213.

13. Abubakar NS, Florence IO, Iyanu OO (2014) Phytochemical Screening and Hypoglycemic effect of Methanolic fruit extract of Cucumis sativus in alloxan induced diabetic rats. Journal of Medicinal Plant Research 8(39): 1173-1178.

14. Galgani J, Aguirre C, Díaz E (2006) Acute effect of meal glycemic index and glycemic load on blood glucose and insulin responses in humans. Nutr J 5: 22.

15. Ball SD, Keller KR, Moyer-Mileur LJ, Ding YW, Donaldson D, et al. (2003) Prolongation of satiety after low versus moderately high glycemic index meals in obese adolescents. Pediatrics 111(3): 488-494.

16. Grover JK, Vats V, Rathi SS (2000) Antihyperglycemic effect of Eugenia jambolana and Tinospora cordifolia in experimental diabetes and their effects on key metabolic enzymes involved in carbohydrate metabolism. J Ethnopharmacol 73(3): 461-470.

17. Ezekwe, Sunday A, Ify E, Uzoma OK (2014) Hypoglycemic, hypolipidemic and body weight effects of unripe pulp of Carica papaya using diabetic Albino rat model. Journal of Pharmacognosy and Phytochemistry 2(6): 109-114.

18. Agrawal Supriya, Katare Charu (2015) Antioxidant activity, total phenolic compound and flavonoid content of vaccum dreid extract of Ll Siceraria. Global journal of multidisciplinary studies 4(6): 302-308.

19. Prakongpan T, Nitihamyong A, Luangpituksa P (2002) Extraction and application of DFand cellulose from pineapple cores. J Food Sci 267(4): 1308-1313.

20. Eshak ES, Iso H, Date C, Kikuchi S, Watanabe Y, et al. (2010) Dietary fiber intake is associated with reduced risk of mortality from cardiovascular disease among Japanese men and women. J Nutr 140(8): 1445-1453.

21. Hopping BN, Erber E, Grandinetti A, Park SY, Kolonel LN, et al. (2010) Dietary fiber, magnesium, and glycemic load alter risk of type 2 diabetes in a multiethnic cohort in Hawaii. J Nutr 140(1): 68-74.

22. Nazare JA, Sauvinet V, Normand S, Guerin DL, Gabert L, et al. (2011) Impact of a resistant dextrin with a prolonged oxidation pattern on day-long ghrelin profile. J Am Coll Nutr 30(1): 63-72.

23. Schulze MB, Liu S, Rimm EB, Manson JE, Willett WC, et al. (2004) Glycemic index, glycemic load, and DFintake and incidence of type 2 diabetes in younger and middle-aged women. Am J Clin Nutr 80(2): 348-356. 
This work is licensed under Creative Commons Attribution 4.0 Licens

DOI:10.19080/JCMAH.2017.02.555593

\section{Your next submission with Juniper Publishers} will reach you the below assets

- Quality Editorial service

- Swift Peer Review

- Reprints availability

- E-prints Service

- Manuscript Podcast for convenient understanding

- Global attainment for your research

- Manuscript accessibility in different formats

( Pdf, E-pub, Full Text, Audio)

- Unceasing customer service

Track the below URL for one-step submission https://juniperpublishers.com/online-submission.php 